\title{
Elevated IL-4 and IFN- $\gamma$ Levels in Muscle Tissue of Patients with Dermatomyositis
}

\author{
MURAT GIRIŞ $^{1}$, HACER DURMUŞ ${ }^{2}$, BERRAK YETIMLER ${ }^{1}$, \\ HATICE TAŞLI $^{2}$, YEŞIM PARMAN ${ }^{2}$ and ERDEM TÜZÜN ${ }^{1}$ \\ ${ }^{1}$ Department of Neuroscience, Aziz Sancar Institute for Experimental Medical Research, and \\ ${ }^{2}$ Department of Neurology, Istanbul Faculty of Medicine, Istanbul University, Istanbul, Turkey
}

\begin{abstract}
Background/Aim: To investigate the contribution of muscle tissue-derived cytokines in dermatomyositis (DM). Materials and Methods: Muscle homogenates were prepared from deltoid muscle biopsy specimens of 10 patients with DM and eight controls with no pathological signs of myopathy. Interleukin (IL)-4, interferon (IFN)- $\gamma$ and IL-17 levels were evaluated by enzyme-linked immunosorbent assay (ELISA) and immunoblotting analysis. Muscle strength grades were recorded. Results: Patients with DM showed significantly elevated muscle tissue IL-4 and IFN- $\gamma$ levels, whereas IL-17 levels were comparable between patients with DM and controls. Immunoblotting studies confirmed ELISA results. In DM muscle specimens, IL-4 and IFN- $\gamma$ levels were positively correlated, while no correlation was observed between $I L-17$ and the other two cytokines. Moreover, IL-4 and IFN- $\gamma$ levels were significantly negative correlated with muscle strength grades for the deltoid muscle. Conclusion: Our results confirm the involvement of Thelper (Th) 1-type and Th2-type immunity in DM pathogenesis. Muscle tissue appears to contribute to muscle weakness in DM by producing inflammatory cytokines.
\end{abstract}

Dermatomyositis (DM) is characterized by inflammation of the muscles and the skin, and elevated creatine kinase levels. The muscle pathological findings include inflammatory cells [predominantly B and $\mathrm{CD}^{+}{ }^{+}$T-helper (Th) cells], vasculitis and perifascicular atrophy. DM-related vasculitis is characterized by membrane attack, complex deposits, endothelial necrosis and capillary loss (1).

This article is freely accessible online.

Correspondence to: Erdem Tüzün, MD, Department of Neuroscience, Aziz Sancar Institute for Experimental Medical Research, Istanbul University, Istanbul, Turkey. Tel.: +90 2124142000 ext. 33356, Fax: +90 2125334393, e-mail: drerdem@yahoo.com

Key Words: Dermatomyositis, interleukin-4, inerleukin-17, interferon-gamma, ELISA.
Infiltrating lymphocytes producing interferon (IFN)- $\gamma$, interleukin (IL)- 4 and IL-17 have been demonstrated in muscle biopsy specimens from patients with DM, signifying the involvement of different Th types in this disease $(2,3)$. Myocytes and endothelial cells are known to produce cytokines, particularly under inflammatory conditions, and undergo cell death when exposed to inflammatory cytokines (4-6). Therefore, not only infiltrating lymphocytes but also the muscle tissue as a whole might presumably contribute to chronic muscle inflammation and cytokine-induced tissue damage in an autocrine fashion. Nevertheless, the muscle tissue as a single cytokine producing unit has been vastly understudied in DM.

In order to investigate the involvement of muscle tissue in DM, signature cytokines of Th1 (IFN- $\gamma$ ), Th2 (IL-4) and Th17 (IL-17)-type immunity were measured in muscle biopsy specimens from patients with DM and a potential correlation between cytokine levels and muscle weakness was investigated.

\section{Materials and Methods}

Patients. Muscle biopsy samples from 10 newly diagnosed active patients with DM (age $=48.5 \pm 19.1$ years; three men, seven women) satisfying Bohan and Peter's criteria of definite DM (7) were evaluated. Age and gender-matched controls (age $=49.6 \pm 20.3$ years; two men, six women) included eight patients presenting with nonspecific muscle manifestations but normal muscle histology. Muscle biopsy samples were obtained from deltoid muscle under local anesthesia within the first 3 months of disease onset. The biopsy specimens were snap-frozen in liquid nitrogen and stored at $-80^{\circ} \mathrm{C}$ until analysis. None of the patients were under immunosuppressive treatment during biopsy. Medical Research Council (MRC) Scale grades of the deltoid muscles used for biopsy were recorded. The study protocol was approved by the Institutional Review Board (Approval Number: 2016-22073).

Enzyme-linked immunosorbent assay (ELISA). Frozen muscle biopsy samples were thawed, weighed and $1 \mathrm{~g}$ muscle tissue per patient was transferred to tubes on ice containing $50 \mathrm{mM}$ Tris- $\mathrm{HCl}$ $(\mathrm{pH} 7.4), 150 \mathrm{mM} \mathrm{NaCl}, 1 \%$ Triton $\mathrm{X}-100,0.5 \%$ sodium deoxycholate, $0.1 \%$ sodium dodecyl sulfate (SDS), $1 \mathrm{mM}$ 
A

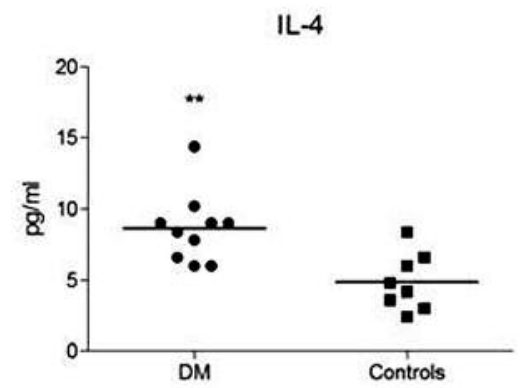

C

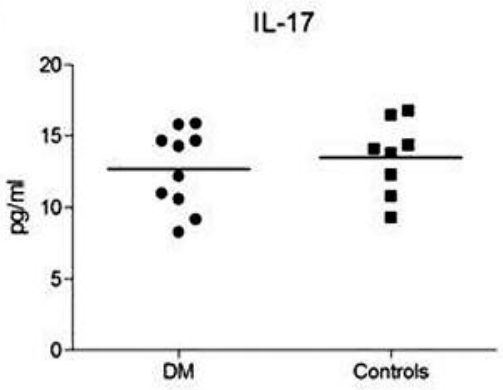

B

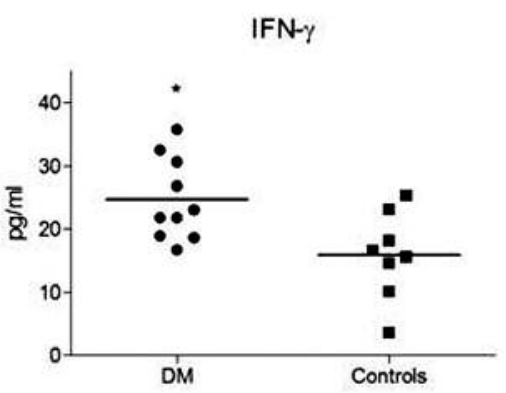

D

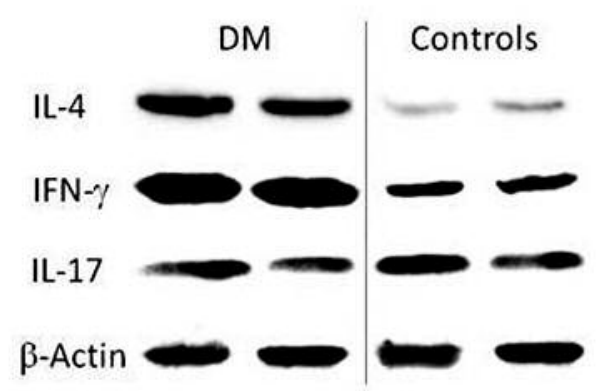

Figure 1. Levels of interleukin (IL)-4 (A), interferon $(I F N)-\gamma(B)$ and IL-17 (C) were determined in muscle homogenates from patients with DM and control patients by ELISA. Representative immunoblot bands showing expression of IL-4,IFN- $\gamma$ and IL-17 in muscle homogenates of patients with dermatomyositis (DM) and control patients. Horizontal lines in panels A-C indicate mean values. Significantly different at $* p<0.05$ and $* * p<0.01$ (D). $\beta$-Actin bands were used as a loading control.

phenylmethylsulfonyl fluoride, $10 \mu \mathrm{g} / \mathrm{ml}$ aprotinin and $10 \mu \mathrm{g} / \mathrm{ml}$ soy bean trypsin inhibitor. Muscle samples were homogenized at $4^{\circ} \mathrm{C}$ and centrifuged at $13000 \times g$ at $4^{\circ} \mathrm{C}$ for 20 minutes. Total protein concentration was determined in the supernatant by a BCA kit (Sigma-Aldrich, St. Louis, MO, USA). Samples were diluted with assay diluent and brought to a final protein concentration of 200 $\mu \mathrm{g} / \mathrm{ml}$. Levels of IL-4, IFN- $\gamma$ and IL-17 were measured by ELISA as per manufacturer's instructions (Diaclone, Besancon, France) based on a standard curve. Results are expressed as $\mathrm{pg} / \mathrm{ml}$.

Immunoblotting analysis. Twenty micrograms of each muscle homogenate sample was loaded and separated by $4-20 \%$ SDSpolyacrylamide gradient gel electrophoresis and then transferred to $0.45-\mu \mathrm{m}$ polyvinylidene fluoride membranes (100 V, $80 \mathrm{~min}$ ). After blocking for 1 hour in phosphate-buffered saline with Tween 20 (PBST) containing 5\% non-fat dry milk, blots were incubated overnight at $4{ }^{\circ} \mathrm{C}$ with primary antibodies to IL-4, IFN- $\gamma$ and IL-17 (diluted 1:200; Santa Cruz Biotechnology, Santa Cruz, CA, USA) in PBST. The blots were washed with PBST and incubated for 1 hour with horseradish peroxidase-conjugated secondary antibody (Santa Cruz Biotechnology) in PBST. Immunoreactivity of the protein bands were detected by enhanced chemiluminescent autoradiography (ECL kit;Amersham Pharmacia Biotech, Piscataway, NJ, USA).

Statistical analysis. Cytokine levels in muscle tissue were compared using Student's $t$-test. Correlation between cytokine levels was analyzed by Pearson's parametric correlation test, whereas correlation between muscle grade strength and cytokine levels was investigated with Spearman's non-parametric correlation test. A pvalue of less than 0.05 was accepted as statistically significant.

\section{Results}

Muscle tissue homogenates from patients with DM have elevated IL-4 and IFN- $\gamma$ levels. In ELISA studies, patients with DM had significantly higher IL-4 $(p=0.003)$ and IFN- $\gamma$ $(p=0.014)$ levels than controls, whereas no significant difference was found is IL-17 level $(p=0.527)$ between patients with DM and controls (Figure 1A-C). Similarly to the ELISA results, immunoblot analysis showed thicker IL-4 and IFN- $\gamma$ bands in samples from patients with DM, whereas the IL-17 bands were comparable in patients with DM and controls (Figure 1D).

Correlation between cytokine levels and muscle strength grades. In muscle samples from controls, significant positive correlation was found between levels of IL-4, IFN- $\gamma$ and IL17 (Figure 2A, lower panels). By contrast, in muscle samples from patients with DM, IL-17 levels were not significantly correlated with IL-4 and IFN- $\gamma$ levels, while there was a strong positive correlation between IL-4 and IFN- $\gamma$ levels (Figure 2A, upper panels). Notably, IL-4 and IFN- $\gamma$ levels but not IL-17 levels were significantly negatively correlated 
A

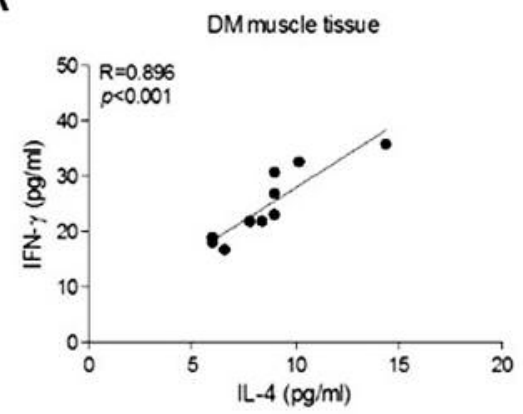

Control muscle fssue

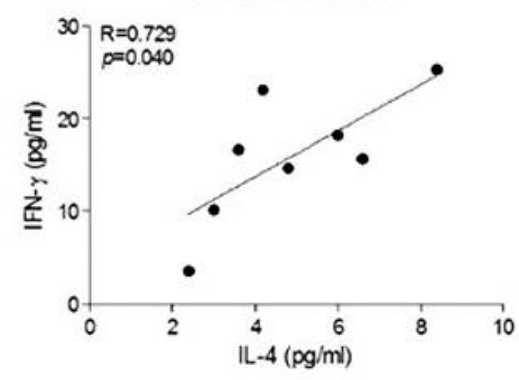

B

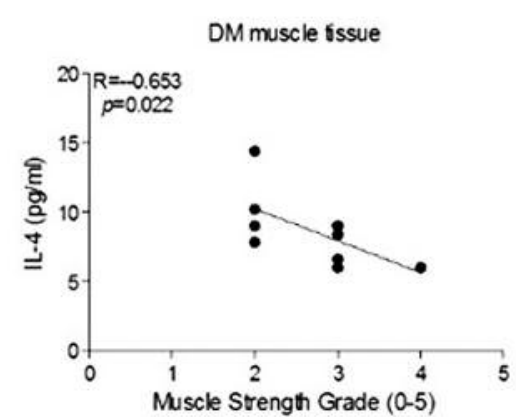

DM muscle tissue

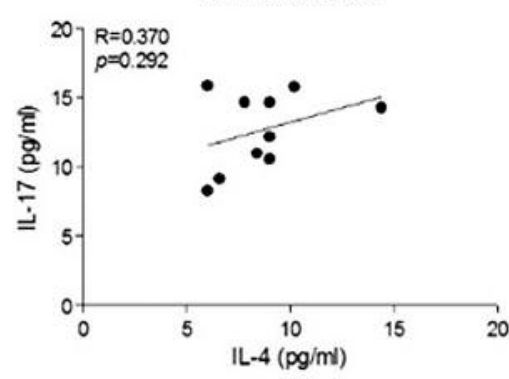

Control muscle tissue

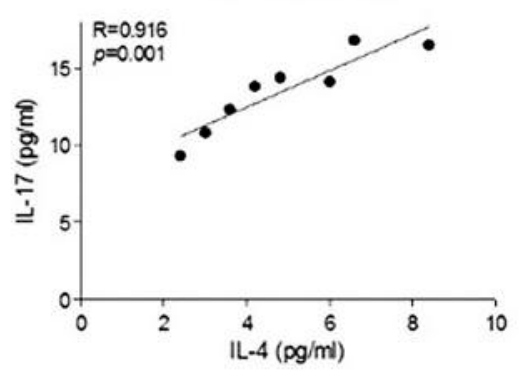

DMmuscle tissue

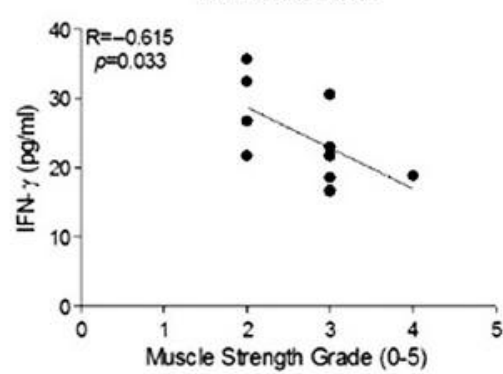

DM muscle tssue

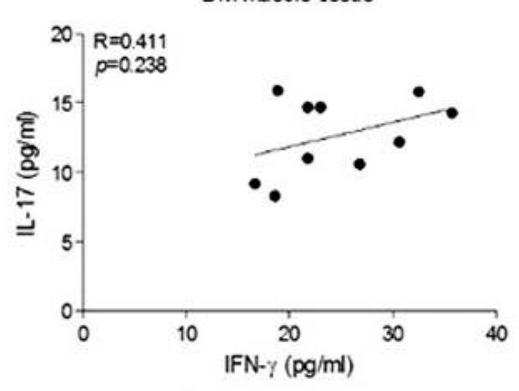

Control muscle tssue

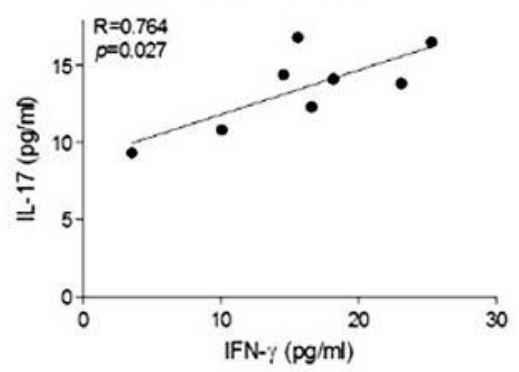

DM muscle tssue

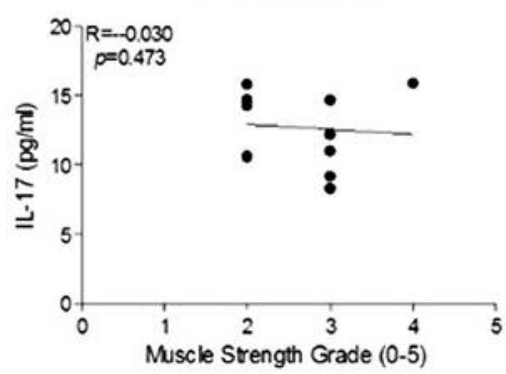

Figure 2. Correlations between cytokine expression levels in muscle homogenates of dermatomyositis (DM) and control patients (A) and between muscle strength grades and cytokine expression levels $(B)$. p-Values are for Pearson's correlation test in panel A and Spearman's correlation test in panel B.

with MRC grades of the deltoid muscle from which the muscle biopsies were obtained (Figure 2B).

\section{Discussion}

Elevated levels of the signature cytokines of Th1 (IFN- $\gamma$ ) and Th2 (IL-4)-type immunity have been shown in serum and peripheral blood mononuclear cells (PBMCs) of patients with DM (8). IL-4- and IFN- $\gamma$-producing T-cells were also demonstrated in the inflammatory infiltrates of muscle and skin lesions (2) and increased IL- 4 and IFN- $\gamma$ mRNA levels were found in muscle tissue samples of patients with DM (9). We studied major Th cytokines produced by muscle tissue at the protein level since discrepancies between cytokine mRNA and protein levels are known to occur (10). Similarly to previous studies, elevated IL-4 and IFN- $\gamma$ levels were found in patients with DM, corroborating the role of Th1- and Th2-immunity in DM pathogenesis.

More importantly, muscle tissue IL-4 and IFN- $\gamma$ levels were negatively correlated with MRC scores. Higher IL-4 and IFN- $\gamma$ levels in patients with lower MRC grades suggest that Th1 and Th2-type cytokines are produced in higher amounts in parallel with progression of muscle weakness.

Increased IL-17 levels have been shown in serum, PBMCs and muscle cell-infiltrating T-cells of patients with DM (2, 8 , 9). However, we failed to show an increase in IL-17 
production by muscle tissue. This contradicts another study demonstrating increased muscle tissue IL-17 production in DM (11). Inclusion of probable patients with DM and longer average DM duration in the previous study might be potential reasons for this discrepancy. In addition, in contrast to semi-quantitatively evaluated immunoblot methods used in previous studies, we assessed cytokine levels with a more accurate quantitative ELISA method. Th2/Th17 and Th1/Th17 ratios were previously found to be elevated in peripheral blood and muscle-infiltrating T-cells suggesting that Th17 activation occurs at a lesser magnitude in DM than other Th- related immunity $(8,12)$. Moreover, IL-17 levels were not correlated with severity of muscle weakness in our study. Overall, these findings suggest that IL-17 is less profoundly involved in DM pathogenesis.

Notably, IL-4, IFN- $\gamma$ and IL-17 levels were correlated in muscle tissue from controls, indicating that different types of Th-related immunity factors regulate and modulate each other in non-inflamed muscle tissue. This control mechanism appears to be disrupted in DM, presumably due to mediators and cytokines released from infiltrating cells and vasculitic blood vessels. In fact, IL-4 and IFN- $\gamma$ have both been shown to suppress Th17-type immune responses $(13,14)$.

In conclusion, our results suggest that in DM, muscle tissue increases production of IL- 4 and IFN- $\gamma$, which are possibly involved in muscle weakness. Whether IL-4 and IFN- $\gamma$ directly attenuate muscle cell survival and function needs to be further studied.

\section{Conflicts of Interest}

The Authors declare that they have no conflict of interest.

\section{References}

1 Cavazzana I, Fredi M, Selmi C, Tincani A and Franceschini F: The clinical and histological spectrum of idiopathic inflammatory myopathies. Clin Rev Allergy Immunol 52: 88-98, 2017.

2 Fujiyama T, Ito T, Ogawa N, Suda T, Tokura Y and Hashizume $\mathrm{H}$ : Preferential infiltration of interleukin-4-producing CXCR4+ T-cells in the lesional muscle but not skin of patients with dermatomyositis. Clin Exp Immunol 177: 110-120, 2014.

3 Page G, Chevrel G and Miossec P: Anatomic localization of immature and mature dendritic cell subsets in dermatomyositis and polymyositis: Interaction with chemokines and Th1 cytokine-producing cells. Arthritis Rheum 50: 199-208, 2004.

4 Pedersen BK and Febbraio MA: Muscle as an endocrine organ: focus on muscle-derived interleukin-6. Physiol Rev 88: 13791406, 2008.
5 Zhang C: The role of inflammatory cytokines in endothelial dysfunction. Basic Res Cardiol 103: 398-406, 2008.

6 Tüzün E, Li J, Wanasen N, Soong L and Christadoss P: Immunization of mice with T-cell-dependent antigens promotes IL-6 and TNF-alpha production in muscle cells. Cytokine 35: 100-106, 2006.

7 Bohan A and Peter JB: Polymyositis and dermatomyositis (first of two parts). N Engl J Med 292: 344-347, 1975.

8 Shimojima Y, Ishii W, Matsuda M and Ikeda S: Phenotypes of peripheral blood lymphocytes and cytokine expression in polymyositis and dermatomyositis before treatment and after clinical remission. Clin Med Insights Arthritis Musculoskelet Disord 5: 77-87, 2012.

9 Kim GT, Cho ML, Park YE, Yoo WH, Kim JH, Oh HJ, Kim DS, Baek SH, Lee SH, Lee JH, Kim HY and Kim SI: Expression of TLR2, TLR4, and TLR9 in dermatomyositis and polymyositis. Clin Rheumatol 29: 273-279, 2010.

10 Ciccia F, Rizzo A, Alessandro R, Guggino G, Maugeri R, Saieva L, Cannizzaro A, Giardina A, De Leo G, Gerardo Iacopino D and Triolo G: Activated IL-22 pathway occurs in the muscle tissues of patients with polymyositis or dermatomyositis and is correlated with disease activity. Rheumatology 53: 1307-1312, 2014.

11 Yin Y, Li F, Shi J, Li S, Cai J and Jiang Y: MiR-146a Regulates inflammatory infiltration by macrophages in polymyositis/ dermatomyositis by targeting TRAF6 and affecting IL17/ICAM-1 pathway. Cell Physiol Biochem 40: 486-498, 2016.

12 Tournadre A, Porcherot M, Chérin P, Marie I, Hachulla E and Miossec P: Th1 and Th17 balance in inflammatory myopathies: interaction with dendritic cells and possible link with response to high-dose immunoglobulins. Cytokine 46: 297-301, 2009.

13 Lee J, Lee J, Park MK, Lim MA, Park EM, Kim EK, Yang EJ, Lee SY, Jhun JY, Park SH, Kim HY and Cho ML: Interferon gamma suppresses collagen-induced arthritis by regulation of Th17 through the induction of indoleamine-2,3-deoxygenase. PloS One 8: e60900, 2013.

14 Guenova E, Skabytska Y, Hoetzenecker W, Weindl G, Sauer K, Tham M, Kim KW, Park JH, Seo JH, Ignatova D, Cozzio A, Levesque MP, Volz T, Köberle M, Kaesler S, Thomas P, Mailhammer R, Ghoreschi K, Schäkel K, Amarov B, Eichner M, Schaller M, Clark RA, Röcken M and Biedermann T: IL-4 abrogates $\mathrm{T}(\mathrm{H}) 17$ cell-mediated inflammation by selective silencing of IL-23 in antigen-presenting cells. Proc Natl Acad Sci USA 112: 2163-2168, 2015. 